\title{
EFFECT OF VARIABLE PHACO TIMES OF CONSTANT PHACO POWER ON MACULAR THICKNESS
}

\author{
By

\section{Mohammed El-Sayed El-Ymany Abo Karemh, Magdy Ezzat Khallaf and Hossam El-Din Abd El-Monem Ziada}

Departments of Ophthalmology, Faculty of Medicine, Al-Azhar University

Corresponding author: Mohammed El-Sayed El-Ymany Abo Karemh, Mobile: 01098032297, E-mail: mohamedelymany391@gmail.com

\begin{abstract}
Background: Various factors involved in phaco can influence the tissue structures of the eyeball Ultrasonic energy should be taken into consideration as a risk factor that may affect the structure of the tissue in the eyeball.

Objective: To evaluate changes on macular thickness before and after phacoemulsification surgery with variable Phaco Times and constant phaco power by Optical Coherence Tomography (OCT).

Patients and methods: A prospective observational clinical study on 40 eyes with Nuclear cataract grade IIIII. All patients under went full medical and ophthalmic history, history of ocular surgeries, complete ophthalmic examination include ingvisual acuity: Uncorrected VA (UCVA) and best corrected VA (BCVA),Anterior segment examination using Slit-lamp bio microscopy, Intraocular pressure (IOP) measurement by applanation tonometry, Fundus examination, OCT was done preoperatively and then 4-6 weeks postoperatively.
\end{abstract}

Results: In patients with Nuclear cataract, there was no significant correlation between postoperative 4-6 weeks macular thickness (MT) with phaco time.

Conclusion: After phacoemulsification surgery with variable phaco times and constant phaco power, there was no significant correlation between postoperative 4-6 weeks macular thickness (MT) with phaco time.

Keywords: Optical Coherence Tomography, Intraocular pressure, macular thickness.

\section{INTRODUCTION}

Phacoemulsification is one of the most widely used cataract surgery techniques nowadays. Various factors involved in phaco can influence the tissue structures of the eyeball. Unlike other maneuvers, ultrasonic energy and fluidics produce mechanical effects that cause an tissue inflammatory reaction, compression, and hypoxia on the tissue. Every step of this procedure can cause direct effects on tissue and instantaneous pressure fluctuation. Ultrasonic energy should be taken into consideration as a risk factor that may affect the structure of the tissue in the eyeball. In this case, phaco surgeons can measure the ultrasonic energy that was emitted through the phaco time (Gede etal., 2013).

Effective phaco time: It is determined by the phaco machine. During the surgery, the surgeon uses various percentage of 
phaco energy from zero to preset for complete nucleus management (actual phaco time). Machine denotes that if surgeon uses its preset values all the time for nucleus management, it will take less duration than needed. This time calculated by the machine is called as effective phaco time (Navneet, 2013).

The retina, a sensory array, is in need to more oxygen as compared to the brain and; accordingly, is affected by the alterations in the levels of oxygen, and in the condition of the eyeball ( $\mathrm{Hac}$ et al., 2016).

Cystoid-macular edema following cataract surgery is a known complication and has been postulated due to the release of inflammatory mediators that affect the blood retinal barrier and results in increased permeability of the parafoveal and perifoveal capillaries with fluid accumulation in the retina (Chaudhary et al., 2014).

Optical coherence tomography (OCT) is a noninvasive objective ocular imaging technology providing cross-sectional images of the in vivo tissues at a micrometer resolution scale (Ashok, 2014).

The present work aimed to evaluate changes on macular thickness before and after phacoemulsification surgery with variable Phaco Times and constant phaco power by OCT.

\section{PATIENTS AND METHODS}

This study was conducted in Ophthalmology Department at Cairo Fatemic Hospital; It was approved by the Ethics Board of Al-Azhar University.
The presented study included 40 eyes of 40 patients. All patients were admitted for Phacoemulsification cataract surgery and foldable posterior chamber IOL implantation. Patients were recruited from the general clinic of Cairo Fatemic hospital during the period from December, 2018 to September, 2019. OCT was done at Cairo Fatemic Hospital. Approval for the study was obtained from the hospital's ethical committee. All patients received a thorough explanation of the study design and aims, and were provided with written informed consent.

\section{Inclusion criteria:}

Patients with Nuclear cataract grade II - III, age from 50years: 70 years, Macula free clinically and by OCT.

\section{Exclusion criteria:}

Diabetic patients, hypertensive patients, glaucomatous patients, uveitic patients.

\section{Intervention and outcome measures:}

1. Thorough history taking including: Age, sex, detailed visual complaints, past ocular history (disease \& surgery) and other associated systemic diseases.

2. Ocular examination: Best corrected visual acuity (BCVA)in decimal scale formatting was donepreoperatively.

Preoperative anterior segment was examined by slit lamp bio microscopy to assess cataract density. Measurement of intraocular pressure (IOP) was done by Goldmann's applanation tonometer. Preoperative fundus was examined by slit lamp bio microscopy with the +90 D lens to assess macular status and peripheral retina. 
3. Optical coherence tomography: Pupils were dilated for OCT examination in all cases with $1 \%$ tropicamide(Mydriacyl).

OCT was done preoperatively and then 4-6 weeks postoperatively. OCT using TOPCON DRI OCT Triton (plus) Swept source OCT $1050 \mathrm{~nm}$ wave length. Retinal thickness was measured with radial lines (16 lines overlap). The scan Diameter is $6.0 \mathrm{~mm}$. It consists of two circular maps divided into nine areas centered on macula of each eye. Only mean foveal thickness was studied; which represents the mean thickness of a foveal area of a diameter of $1000 \mu \mathrm{m}(1 \mathrm{~mm})$.

\section{Phacoemulsification procedure:}

Phacoemulsification and intraocular lens insertion were performed using almost the standard techniques. Before surgery, all pupils were dilated with $1 \%$ tropicamide (Mydriacyl), also ocular sterilization with povidine iodine $5 \%$ was used. Cataract surgery was performed under local anesthesia, anterior limbal scratch incision was made using keratome, two side ports was made by micro vitreoretinal plade (MVR). Epinephrine solution was used in eight patients. Formation of the anterior chamber by viscoelastic material. Capsulorhexis was performed under viscoelastic material Hydrodissection and hydrodelineation. Phacoemulsification of the nucleus. Computing of phaco time Bimanual irrigation aspiration. Implantation of foldable intraocular lens in the bag by injector through the wound. Finally, hydration of the wound and the 2 paracentesisopenings. All patients received the same standard medications, consisting of a combination of steroidal eye drops(Prednisolone acetate), 1 drop every 6 hours for 1 week, then 1 drop every 8 hours for 2 weeks, then 1 drop every 24 hours for 1 week and antibiotic (Gatifloxacin) eye drops 4 times daily for 10 days.

\section{Follow up:}

Clinical examination after one week and one month postoperatively including best corrected visual acuity and fundus examination. OCT was done after 4 -6 weeks postoperatively where the occurrence of pseudophakic macular edema peaks at approximately 4-6 weeks postoperatively.

\section{Statistical analysis:}

Data were analyzed using Statistical package for the Social Science (IBM SPSS) version 20.0. Quantitative data were expressed as mean \pm standard deviation (SD). Qualitative data were expressed as frequency and percentage.

The following tests were done: Paired t-test of significance: was used when comparing between two means.

P-value $<0.05$ was considered significant. 


\section{RESULTS}

The BCVA increased with highly significant degree from $0.23 \pm 0.15$ on to
$0.61 \pm 0.13$ four weeks postoperatively $(\mathrm{p}<0.001)$ (Table1).

Table (1): Comparison between preoperative,and 4-6 weeks postoperative best corrected visual acuity

\begin{tabular}{|c|c|c|}
\hline \multicolumn{2}{|c|}{ BCVA } & No. $=40$ \\
\hline \multirow{2}{*}{$\begin{array}{c}\text { Preoperative best } \\
\text { corrected visual acuity }\end{array}$} & Mean \pm SD & $0.23 \pm 0.15$ \\
\hline & Range & $0.05-0.50$ \\
\hline \multirow{2}{*}{$\begin{array}{c}\text { Postoperative best } \\
\text { corrected visual acuity }\end{array}$} & Mean \pm SD & $0.61 \pm 0.13$ \\
\hline & Range & $0.20-0.90$ \\
\hline \multirow{2}{*}{ Mean difference } & Mean \pm SD & $0.38 \pm 0.14$ \\
\hline & Range & $0.1-0.74$ \\
\hline \multicolumn{2}{|c|}{ Paired t-test } & -16.706 \\
\hline \multicolumn{2}{|c|}{$\mathrm{P}$-value } & $<0.001(\mathrm{HS})$ \\
\hline
\end{tabular}

The CMT increased with highly significant degree from $(252.00 \pm 23.56)$ preoperative to $(268.40 \pm 29.45) \quad 4-6$ weeks postoperatively

(Table 2).

Table (2): Preoperative and 4-6 weeks postoperative central macular thickness

\begin{tabular}{|l|l|c|}
\hline \multicolumn{2}{|c|}{ CMT $(\mu)$} & No. $=40$ \\
\hline \multirow{2}{*}{ Preoperative macular thickness } & Mean \pm SD & $252.00 \pm 23.56 \mu \mathrm{m}$ \\
\cline { 2 - 3 } & Range & $197-306 \mu \mathrm{m}$ \\
\hline \multirow{2}{*}{ Postoperative macular thickness } & Mean \pm SD & $268.40 \pm 29.45 \mu \mathrm{m}$ \\
\cline { 2 - 3 } & Range & $213-341 \mu \mathrm{m}$ \\
\hline \multirow{2}{*}{ Mean difference } & Mean \pm SD & $19.08 \pm 20.10$ \\
\cline { 2 - 3 } & Range & $0-86$ \\
\hline Paired t-test & -4.285 \\
\hline P-value & $<0.001(\mathrm{HS})$ \\
\hline
\end{tabular}

The mean phaco time was estimated during phacoemulsification surgery (Table 3).

Table (3): Operation phaco time

\begin{tabular}{|c|c|}
\hline Phaco time (sec.) & No. $=40$ \\
\hline Mean \pm SD & $94.75 \pm 16.47$ \\
\hline Range & $69-151$ \\
\hline
\end{tabular}

There was no significant correlation between postoperative 4-6 weeks CMT with phaco time (Table 4). 
Table (4): Correlation between preoperative and postoperative 4-6 weeks CMT with phaco time

\begin{tabular}{|l|c|c|}
\hline PMTaco time (sec.) & r & P-value \\
\hline Preoperative macular thickness & -0.111 & 0.495 \\
\hline Postoperative macular thickness & 0.316 & 0.047 \\
\hline
\end{tabular}

$\mathrm{r}=$ Correlation coefficient.

\section{DISCUSSION}

Phacoemulsification is currently the most commonly used technique to remove the cataractous lens using ultrasonic energy. Many studies have shown that phaco provides satisfactory outcomes for patients and is a safe surgery. Phaco related changes in foveal thickness have also been reported (Koç et al., 2016).

The incidence of subclinical macular edema after uneventful cataract surgery has become a safety issue for this frequent operation, as studies have found angiographic leakage up to $19 \%$ postoperatively with OCT, which its peak is detectable 4 to 6 weeks after surgery, in pseudophakic eyes (Eriksson, 2010).

In the present study, the investigation of the effect of phaco time on central macular thickness was measured by OCT, and the results indicated that there was significant increase in thickness from preoperative to 4-6 weeks after cataract surgery.

Although present study included a small group (only 40 eyes), data reliability was high because of the homogeneous nature of the patients (similarities of age, cataract type and severity and phaco power), and the careful/detailed OCT examinations.

Postoperatively, a significant increase in all macular parameters was observed. The change which appeared on day 7 gradually increased by a marked rise in week 4-8 measurement in most of the macular parameters found a significant subclinical increase in macular thickness at postoperative week 1, week 4 and week 8 (Lohani et al., 2020).

The mean CMT postoperatively after one month was significantly higher than the mean thickness after one week preoperatively (Akarsu et al., 2019).

Torkey (2013) significant increase in thickness postoperatively. Present results support the studies by Altintaset al. (2016) who reported significant increases in CMT after uneventful phacoemulsification postoperatively, and Celik et al. (2016) who reported significant increases in CMT after uneventful phacoemulsification. They assumed that data reliability was high because of the homogeneous nature of the patients (similarities of age, cataract type and severity), and the result significantly increased postoperatively.

Koç et al. (2016) reported significant increases in CMT after uneventful phacoemulsification. The mean CMT increased postoperatively.

Gharbiya et al. (2013) stated that no significant correlations were found between retinal thickness changes and both the preoperative and postoperative factors, macular thickness increase with no correlation between macular thickness 
changes and visual acuity. None of the preoperative and intraoperative parameters showed any correlation with retinal thickness changes after surgery.

Protasio and Aguilar (2016) showed that there was a mean change in CMT which is not significant. There was against our study which may be due to race difference as that study was carried out in Philippine.

The BCVA in the present work increased with significant degree postoperatively. Akçay et al. (2012) stated that BCVA increased with significant degree. Nagy et al. (2012) reported that BCVA increased significantly. Celik et al. (2016) found that mean BCVA improved in all eyes, and this improvement was statistically significant. Lohani et al. (2020) mentioned that mean preoperative BCVA improved postoperatively.

The mean phaco time in the present study showed no significant correlation between postoperative 4-6 weeks CMT. Surbhi et al. (2012) found no significant correlation between phaco time and postoperative CMT. Gharbiya et al. (2013) showed no significant correlation between phaco time and CMT postoperatively. Koç et al., (2016) found no significant correlation between phaco time and CMT postoperatively.

Altintas et al. (2016) Phaco Time was not associated with Central Thickness changes and the mean phaco time.

\section{CONCLUSION}

The study was applied on 40 eyes of 40 subjects .The mean age was $61.48 \pm 4.59$. They were 18 females and 22 males with uneventful phacoemulsification and foldable posterior chamber IOL implantation. OCT was used to measure the change of central macular thickness of a diameter of $1000 \mu \mathrm{m}(1 \mathrm{~mm})$ of macular area 4-6 weeks postoperatively.

\section{REFERENCES}

1. Akarsu Açar ÖP., Olgun A., Ergen E., Demir AG. And Guven D. (2019): Evaluation of Changes in Macular Thickness Using Optical Coherence Tomography After Cataract Surgery in Diabetic and Nondiabetic Patients. JAREM; 9(1): 32-7.

2. Akçay B.I., Bozkurt T.K. , Güney E., Ünlü C., Erdogan G., Akcali G., and Bayramlar H.(2012): Quantitative analysis of macular thickness following uneventful and complicated cataract surgery, Clinical Ophthalmology,; 6: 1507-1511.

3. Altintas A.G., Coban P., Arifoglu H.B., Koklu G., Ozcan P.Y.and Sonmez k. (2016): Comparison of phacoemulsification parameters effect on macular thickness changes after uneventful phacoemulsification in diabetic and non - diabetic patients, Int Eye Sci., 16(2): 201-206.

4. Ashok G. (2014): Preface: Anterior and Posterior Segment OCT. Published by Jaypee, $1^{\text {st }}$ edition, USA, 1:17.

5. Celik E., Cakır B., Turkoglu E.B., Dogen E. and Alagos G. (2016): Effect of cataract surgery on subfoveal choroidal and ganglion cell complex thicknesses measured by enhanced depth imaging optical coherence tomography, Clinical Ophthalmology ;10: 2171-2177.

6. Chaudhary C., Bahadhur H. and Gupta N. (2014): Study of cystoid macular edema by optical coherent tomography following uneventful cataract surgery, Int. Ophthalmol., 10:5-8.

7. Eriksson U. (2010): Aspects of Optical Coherent Tomography, faculty of Medicine, Uppsala University, Sweden, Digital comprehensive summaries of Uppsala Dissertations, 2:15-22.

8. Gede P., Nila M., Julia R., Wage S., Satari I., Sembiring R. and Srisamran N. (2013): Retinal thickness changes after 
phacoemulsification, Clinical Ophthalmology.; 7: 2207-2214.

9. Gharbiya M., Cruciani F., Cuozzo G., Parisi F., Russo P., and Abdolrahimzadeh $S$. (2013): Macular thickness changes evaluated with spectral domain optical coherence tomography after uncomplicated phacoemulsification, Eye, 27(5):605-611.

10. Hac K., İbrahim K., Faruk K. and Baybora H. (2016): Effect of Phaco Time on Retinal Thickness, AASCIT Journal of Medicine; 2(2): 23-27.

11. Koç H., Koçak I., Kaya F., and Faruk K. (2016): Effect of Phaco Time on Retinal Thickness, American Journal of Ophthalmology \& Visual Science, 1(1): 1-5.

12. Lohani D., Titiyal G.S., Mehrotra N., and Mehrotra N. (2020): To Evaluate the Changes in Central Macular Thickness After Uncomplicated Phacoemulsification Cataract Surgery Using Optical Coherence Tomography- A Prospective Study, J. Evid. Based Med. Healthc.; 7(7), 322-326.

13. Nagy Z.Z., Ecsedy M., Kovacs I., Takács Á., and Tátrai E. (2012): Macular morphology assessed by optical coherence tomography image segmentation after femtosecond laserassisted and standard cataract surgery, J. Cataract Refract Surg., ;38: 941-946.

14. Navneet T. (2013): Phacoemulsification Machine, simplified Phacoemulsification, Published by Jaypee Brothers Medical Publishers, 1st edition .India. 3:21-35.

15. Protasio J.N. and Aguilar R.N. (2016): Glycemic Control and Changes in Macular Thickness after Phacoemulsification in Diabetics, Journal of Ophthalmology, 41: 2-9.

16. Surbhi A., Uma S., Charu T., and Cruciani F. (2012): To Determine the Incidence of CME after Uneventful Phacoemulsification by OCT, WOC 2012 Abstract Book, 123(10): 146- 149.

17. Torky Z.A.(2013): Evaluation of macular changes after uneventful phacoemulsification surgery in diabetic patients using optical coherence tomography, Ophthalmology Department, Faculty of Medicine, Cairo University, Cairo, Egypt, 2: 5-88. 
تأثير الأوقات الفعلية المتغيرة للموجات فوق الصونية مع

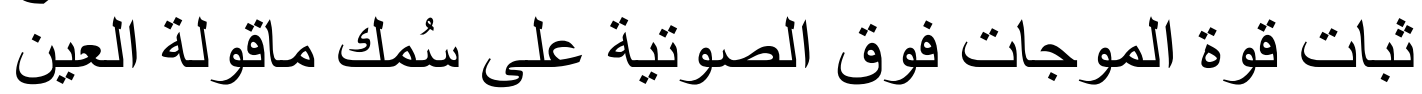
أثناء عملية إستحلاب العدسة

محمد السيد اليمانى أبوكريمة، مجدي عزت خلاف، حسام الدين عبد المنعم زيادة

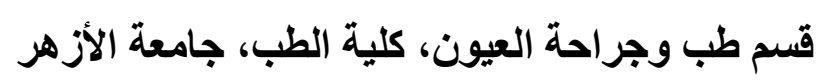

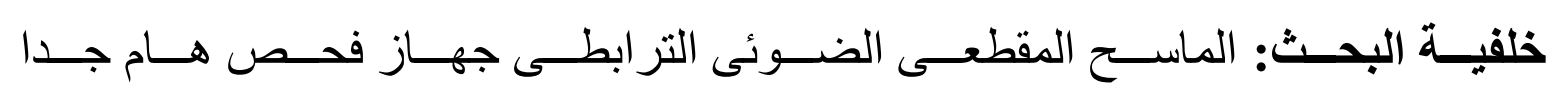

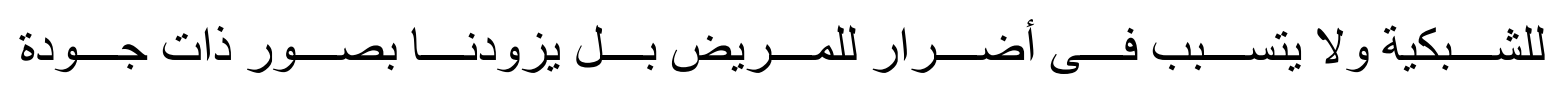
عالية ويعطينا شريحة نسيجية من الخلايا الحية.

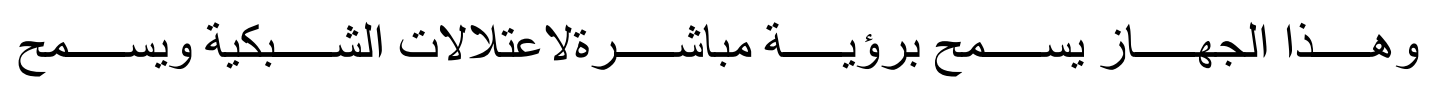

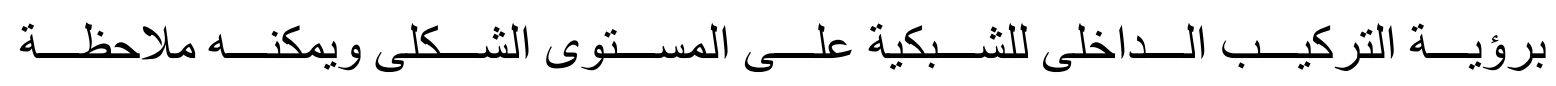
التغيرات البسيطة والتى ربما لا تظهر أثناء الفحص الإكلينيكى.

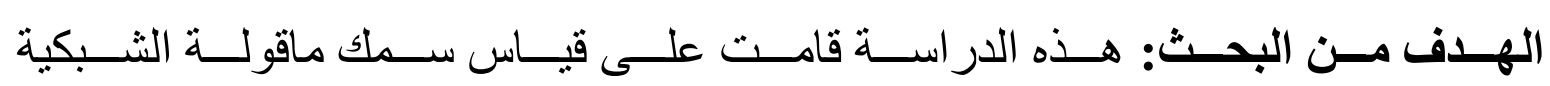

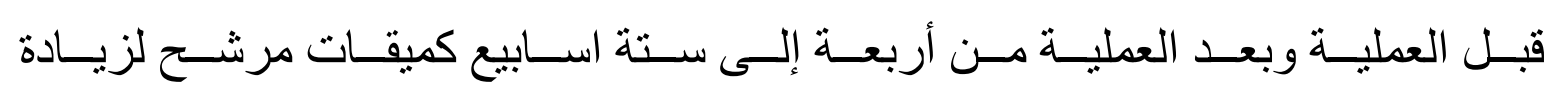

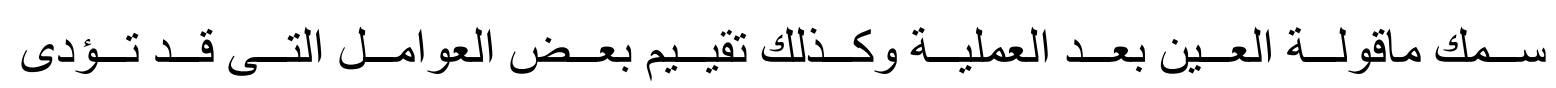

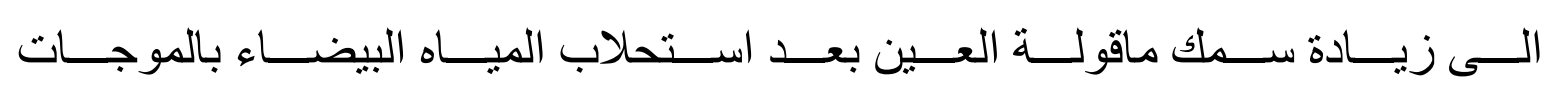
فوق الصوتية والتى لم يحدث لها مشكلات أثناء العملية.

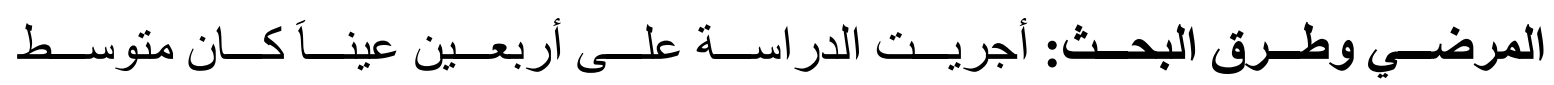

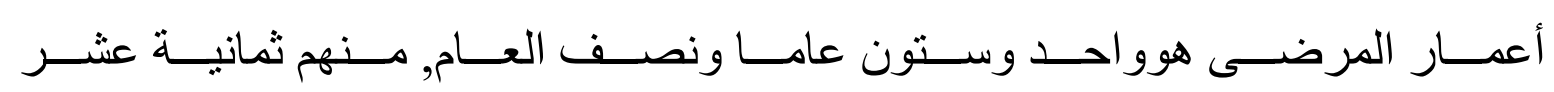

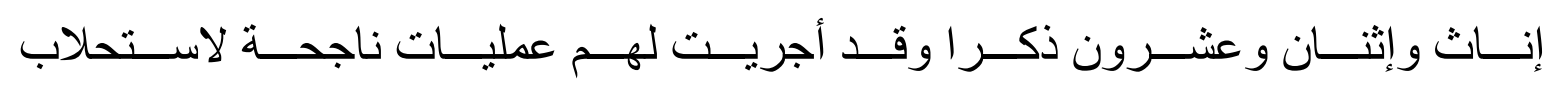

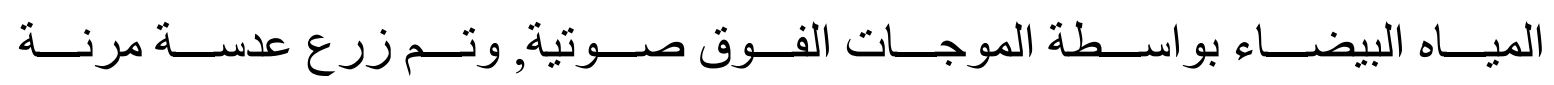

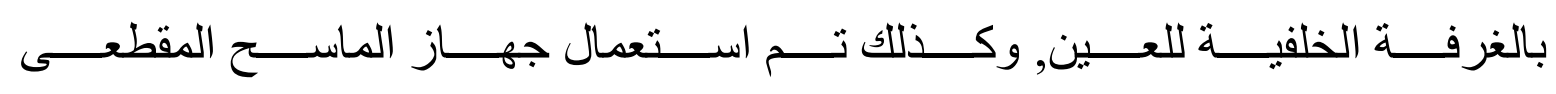

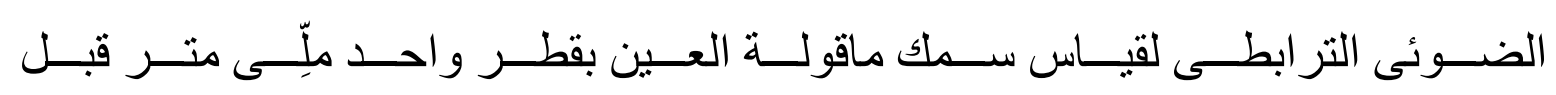
العملية وبعد العملية بأربعة إلى ستة أسابيع. 


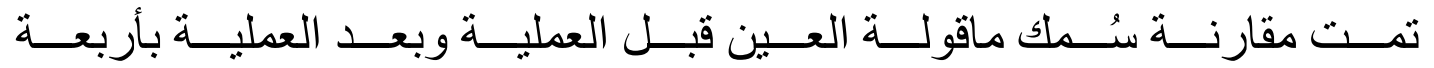

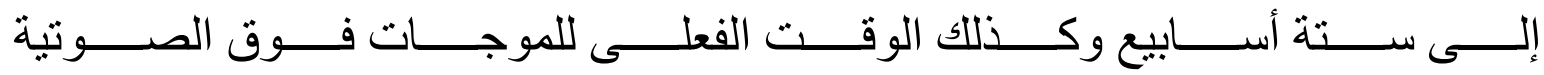

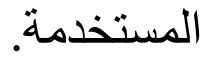

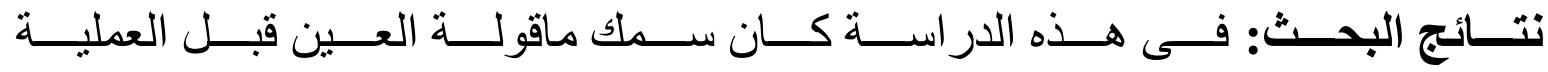

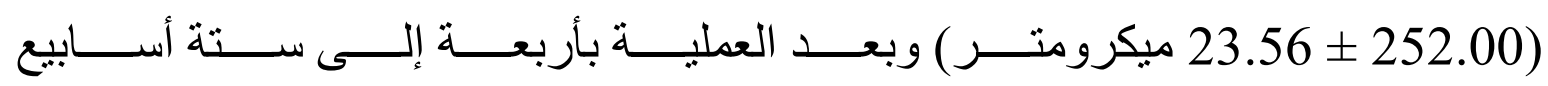

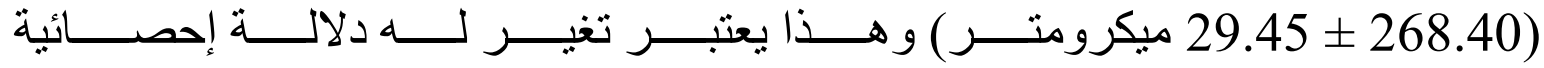

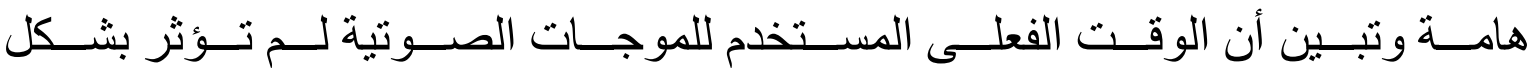
واضح على سمك ماقولة العين بعد العملية بأربعة إلى ستة أسابيع.

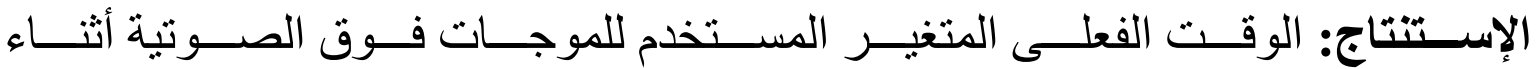

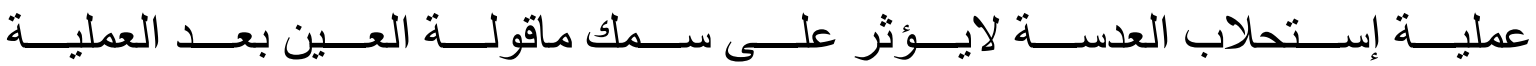
بأربعة إلى ستة أسابيع. 